\title{
Correction to: Short-term clinical and radiographic outcomes of total hip arthroplasty with PMPC-grafted highly cross-linked polyethylene liners against 32-mm femoral heads
}

\author{
Kanto Mouri ${ }^{1} \cdot$ Tatsuro Karita $^{1}[$
}

Published online: 13 March 2021

(c) The Author(s) 2021

\section{Journal of Artificial Organs https://doi. org/10.1007/s10047-020-01246-0}

Unfortunately, the original publication of the article has been published with an error in author's affiliation and abstract section. The correct abstract and affiliation are given in this correction.

In the abstract section, the sentence that reads as "The steady-state wear rate of the PMPC ( 26 or $28 \mathrm{~mm}$ ) group $(0.021 \mathrm{~mm} /$ year) was lower than that of the control (26 or $28 \mathrm{~mm})$ group $(-0.015 \mathrm{~mm} /$ year $)$; the steady-state wear was under the clinical threshold" should read as "The steady-state wear rate of the PMPC ( 26 or $28 \mathrm{~mm}$ ) group $(-0.015 \mathrm{~mm} /$ year) was lower than that of the control (26 or $28 \mathrm{~mm})$ group $(0.021 \mathrm{~mm} /$ year $)$; the steady-state wear was under the clinical threshold".

The article Short-term clinical and radiographic outcomes of total hip arthroplasty with PMPC-grafted highly crosslinked polyethylene liners against 32-mm femoral heads, written by Kanto Mouri and Tatsuro Karita, was originally published electronically on the publisher's internet portal on 15 January 2021 without open access. With the author(s)' decision to opt for Open Choice the copyright of the article changed on 5 February 2021 to $\odot$ The Author(s) 2021 and the article is forthwith distributed under a Creative Commons Attribution 4.0 International License, which permits use, sharing, adaptation, distribution and reproduction in any

The original articles can be found online at https://doi. org/10.1007/s10047-020-01246-0 and https://doi.org/10.1007/ s10047-021-01255-7.

\footnotetext{
Tatsuro Karita

karita-tky@umin.ac.jp

1 Orthopedics Department, Tokyo Metropolitan Tama Medical Center, 2-8-29 Musashidai, Fuchu-shi, Tokyo 183-8524, Japan
}

medium or format, as long as you give appropriate credit to the original author(s) and the source, provide a link to the Creative Commons licence, and indicate if changes were made. The images or other third party material in this article are included in the article's Creative Commons licence, unless indicated otherwise in a credit line to the material. If material is not included in the article's Creative Commons licence and your intended use is not permitted by statutory regulation or exceeds the permitted use, you will need to obtain permission directly from the copyright holder. To view a copy of this licence, visit http://creativecommons .org/licenses/by/4.0/.

Publisher's Note Springer Nature remains neutral with regard to jurisdictional claims in published maps and institutional affiliations. 